\title{
Cost-Utility of All-Oral Direct-Acting Antiviral Regimens for the Treatment of Genotype 1 Chronic Hepatitis C Virus-Infected Patients in Hong Kong
}

\author{
Man-Fung Yuen ${ }^{1,2} \cdot$ Sze-Hang Liu' ${ }^{1} \cdot$ Wai-Kay Seto $^{1,2} \cdot$ Lung-Yi Mak $^{1} \cdot$ Shelby L. Corman ${ }^{3} \cdot$ Danny C. Hsu $^{4}$. \\ Mary Y. K. Lee ${ }^{4}$ Tsz K. Khan ${ }^{4}$. Amy Puenpatom ${ }^{5}$
}

Received: 6 January 2020 / Accepted: 16 April 2020 / Published online: 8 May 2020

(c) The Author(s) 2020

\begin{abstract}
Background Direct-acting antivirals (DAAs) are entering the hepatitis C virus (HCV) treatment landscape in Hong Kong, prompting the need for cost-effectiveness evaluations of these interventions to enable optimal use of healthcare resources. Aims This study aimed to compare the cost-effectiveness of DAAs to standard-of-care pegylated interferon plus ribavirin (RBV) in treatment-naïve patients without significant liver fibrosis and to compare different DAAs in patients who are treatment-experienced and/or have advanced liver disease.

Methods A Markov model was constructed to evaluate cost-effectiveness over a lifetime time horizon from the payer perspective. The target population was treatment-naïve and treatment-experienced HCV genotype 1 patients, stratified by degree of liver fibrosis. The model consists of 16 health states encompassing METAVIR fibrosis score (F0-F4), treatment success or failure, decompensated cirrhosis, hepatocellular carcinoma, liver transplant, and liver-related death. The proportions of patients achieving sustained virologic response were obtained from clinical trials. Other inputs were obtained from published and local data. The primary outcome was incremental cost-utility ratio for each DAA versus pegylated interferon + ribavirin and among different DAAs.

Results In treatment-naïve F0-2 HCV patients, all DAAs were cost-effective in genotype 1a and daclatasvir + asunaprevir, elbasvir/grazoprevir, ledipasvir/sofosbuvir, and glecaprevir/pibrentasvir were cost-effective compared to pegylated interferon + ribavirin in genotype $1 \mathrm{~b}$. In genotypes $1 \mathrm{a}$ and $1 \mathrm{~b}$, treatment-experienced patients, and F3-4 patients, elbasvir/ grazoprevir was the least costly DAA and economically dominant over most other DAAs.

Conclusions DAAs can be a cost-effective option for the treatment of genotype $1 \mathrm{HCV}$ patients in Hong Kong, and elbasvir/ grazoprevir is cost-effective.
\end{abstract}

Keywords Hepatitis C $\cdot$ Chronic $\cdot$ Cost-utility analysis $\cdot$ Direct-acting antiviral agents $\cdot$ Elbasvir/grazoprevir

Shelby L. Corman

scorman@pharmerit.com

1 Department of Medicine, Queen Mary Hospital, The University of Hong Kong, Pok Fu Lam, Hong Kong

2 State Key Laboratory of Liver Disease, The University of Hong Kong, Pok Fu Lam, Hong Kong

3 Pharmerit International, 4350 East-West Highway Suite 1100, Bethesda, MD 20814, USA

4 Merck Sharp \& Dohme (Asia) Ltd., Hong Kong, Hong Kong

5 Merck \& Co., Inc., Kenilworth, NJ, USA

\section{Introduction}

Chronic hepatitis $\mathrm{C}$ (CHC) infection carries a global disease burden as 71 million people are infected worldwide [1]. This disease burden is more pronounced in Western countries compared with their Eastern counterparts. However, in the era of high disease cure rates when treated with direct-acting antivirals (DAAs), there should not be any hindrance to treat patients even in countries with low disease endemicity. In Hong Kong, there are an estimated 11,309 people with $\mathrm{CHC}$ and approximately $49 \%$ are infected with genotype 1 (GT1) hepatitis $\mathrm{C}$ virus (HCV) [2]. Untreated CHC leads to progressive liver fibrosis and cirrhosis and increases patients' risk of 
hepatocellular carcinoma (HCC) and liver-related death, whereas successful CHC treatment and achievement of sustained virologic response (SVR) can result in fibrosis regression, decrease HCC and mortality risks, and improve patients' quality of life [3-7]. In response to the global burden of $\mathrm{CHC}$ and rising hepatitis-related mortality, the World Health Organization (WHO) set a goal in 2016 to eliminate viral hepatitis as a major public health threat by 2030 [8].

Historically, the combination of pegylated interferon (PegIFN) and ribavirin (RBV) was the mainstay of CHC treatment [9]. Telaprevir and boceprevir were the first NS3/4A protease inhibitor DAAs to be marketed worldwide, but were indicated for use only in combination with PegIFN and RBV. All-oral DAAs have emerged in response to unmet need in the treatment of $\mathrm{CHC}$ and provide more convenient dosing regimens with fewer adverse events and drug-drug interactions [10]. These drugs allow for interferon (IFN)-free, RBV-free treatment for many patients, as well as shorter treatment durations. All-oral DAA regimens that are indicated for GT1 infection in various countries around the world include ledipasvir/ sofosbuvir (LDV/SOF), ombitasvir/paritaprevir/ritonavir plus dasabuvir (OMB/PAR/RIT + DAS), sofosbuvir/velpatasvir (SOF/VEL), glecaprevir/pibrentasvir (GLE/PIB), daclatasvir plus asunaprevir (DAC + ASN), and elbasvir/ grazoprevir (EBR/GZR).

Currently, first-line therapy in many countries consists of PegIFN plus RBV (PegIFN + RBV), with DAAs reserved for patients with advanced liver disease. Similar to other countries [11], patients in Hong Kong with a fibrosis stage of F2 or higher are eligible to receive DAAs, but doctors' prescriptions are constrained by budgetary limitations. The uptake of PegIFN + RBV treatment in Hong Kong is low (only $28.4 \%$ of infected patients), and the most common reasons for lack of treatment are contraindications to PegIFN + RBV (17.2\% of infected patients) and treatment refusal (16.1\% of infected patients) [2]. In the same study, nearly half of PegIFN + RBV-treated patients (47\%) discontinued treatment early due to adverse events or lack of efficacy. These data indicate a clear need for more effective and tolerable treatment regimens for $\mathrm{CHC}$ patients in Hong Kong.

As DAAs enter the market in Hong Kong, it is important to evaluate the cost-effectiveness of these interventions to enable optimal use of healthcare resources. The primary objective of the present study was to evaluate the cost-effectiveness of DAAs compared to PegIFN + RBV, the current standard of care, in treatment-naïve (TN) patients with GT1 $\mathrm{CHC}$ infection without advanced liver disease. The secondary objective was to compare EBR/GZR to other DAAs in treatment-experienced (TE) patients as well as TN patients with advanced liver disease.

\section{Methods}

We constructed a Markov state-transition model to assess the cost-effectiveness of DAA and PegIFN + RBV regimens in TN and TE patients with GT1 CHC in Hong Kong from the payer perspective. The model simulates the $\mathrm{CHC}$ disease course, including treatment, cure or treatment failure, and progression of liver disease. Costs and effectiveness are modeled over a lifetime time horizon and are discounted at $3 \%$ per year. Details of the model design and analyses have been described previously [12].

\section{Target Population}

The target population is patients with GT1 CHC in Hong Kong. The model simulated eight cohorts of patients encompassing all combinations of treatment history (TN or TE), HCV subtype (GT1a or GT1b), and degree of fibrosis at treatment initiation (METAVIR scoring system F0-2 or F3-4).

\section{Model Structure}

The model structure was designed to reflect the natural history of HCV infection (Fig. 1) and is consistent with previous models of HCV infection [13-21]. The model was adapted to Hong Kong in accordance with International Society for Pharmacoeconomics and Outcomes Research Good Practices for Economic Modeling [22]. The model was composed of 16 health states, each with a cycle length of one year, with the exception of year 0 in which the cycle length corresponded to the duration of treatment for each arm. Model transitions permitted progression to higher fibrosis stages and worsening complications only, without improvement, except in patients who achieved SVR. The Markov transition probabilities were assumed to be fixed over time.

Patients who achieved SVR on their respective CHC treatment could be reinfected with $\mathrm{HCV}$, with retreatment not included. Patients were assumed not to spontaneously clear CHC infection. Patients who progressed to compensated cirrhosis (F4) were at risk of decompensated cirrhosis (DC) and/or HCC, each of which was discrete health states. Patients who developed DC and/or HCC could receive a liver transplant, which was assumed to increase costs and mortality and decrease utility more in the first year (i.e., LT health state) than in subsequent years (i.e., post-liver transplant [PLT] health state). A similar assumption was made for HCC, with higher costs in the first year, during which treatment was assumed to primarily occur.

It was assumed that liver disease did not further progress in patients who were non-cirrhotic at baseline and achieved 


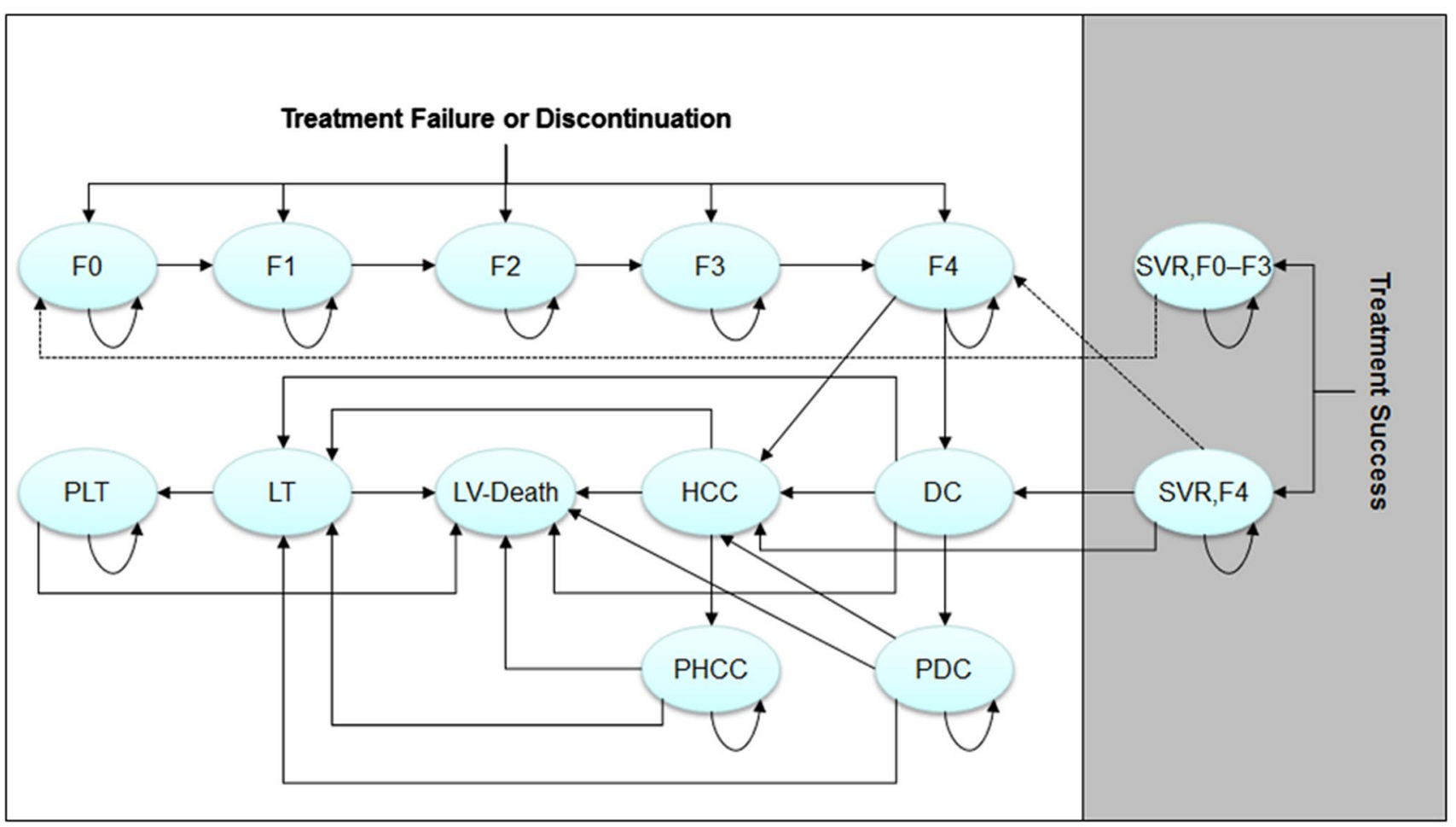

Fig. 1 State transition diagram for chronic HCV and liver disease model. Hepatic fibrosis stage was based on METAVIR fibrosis scoring system: F0, no fibrosis; F1, portal fibrosis without septa; F2, portal fibrosis with few septa; F3, portal fibrosis with numerous septa without cirrhosis; F4, compensated cirrhosis; DC, decompensated

SVR [23, 24]; however, patients who were cirrhotic at baseline were at risk of progression whether or not they achieved SVR. Patients must have progressed to F4 before DC and/ or HCC, and liver transplantation was performed only in patients with DC or HCC. Patients who received a liver transplant were assumed not to be at risk of $\mathrm{CHC}$ reactivation and progression to liver disease. Adverse events and monitoring costs do not differ significantly by treatment regimens and thus are not included.

\section{Model Comparators}

The standard of practice in Hong Kong is for TN F0-2 patients to be treated with PegIFN + RBV. As such, our primary analysis compared EBR/GZR and other DAAs to PegIFN + RBV in TN F0-2 patients. PegIFN + RBV is not typically used in TN F3-4 patients and in TE patients (regardless of fibrosis stage), so EBR/GZR was compared to other DAAs in these patients. DAA regimens that are indicated for GT1 infection in Hong Kong and were included in the model are LDV/SOF, OMB/PAR/RIT + DAS, SOF/ VEL, GLE/PIB, DAC + ASN, and EBR/GZR.

Treatment regimens followed product labeling and standard practice in Hong Kong. For each DAA, the duration of cirrhosis; HCC, hepatocellular carcinoma; LV-death, liver-related death; LT, liver transplant; PDC, one-year post-decompensated cirrhosis; PHCC, one-year post-hepatocellular carcinoma; PLT, postliver transplant; SVR12, sustained virologic response 12 weeks after cessation of treatment

therapy was tailored to HCV subtype (GT1a or GT1b), treatment experience, or presence of cirrhosis. DAC + ASN was assumed to be used only for GT1b patients due to a lack of evidence of efficacy in GT1a infection [25].

\section{Model Inputs}

The proportions of patients achieving SVR for each regimen were obtained from pivotal trials of the model comparators and product labeling (Table 1).

Baseline characteristics of the study population (Table 2) and medication and annual health state costs (Table 3) were obtained from the Hong Kong Public Hospital. Costs were converted from Hong Kong dollars (HKD) to US dollars (US\$) using an exchange rate of $7.8494 \mathrm{HKD}=1 \mathrm{US} \$$ (www.xe.com; accessed May 14, 2019). Clinical inputs that describe the rate of fibrosis progression, rates of liver-related and other-cause mortality, and the probability of requiring and receiving a liver transplant were sourced from the published literature (Table 3).

Age- and sex-specific utility weights were obtained from the published literature and combined with liver diseasespecific utilities and life years gained to calculate total quality-adjusted life years (QALYs) [60]. A treatment-specific 
Table 1 Treatment inputs by subgroup

\begin{tabular}{|c|c|c|c|c|c|}
\hline \multirow[t]{2}{*}{ Treatment regimen } & \multicolumn{2}{|c|}{ Non-cirrhotic (F0-3) } & \multicolumn{2}{|l|}{ Cirrhotic (F4) } & \multirow[t]{2}{*}{ References } \\
\hline & $\begin{array}{l}\text { Duration, } \\
\text { weeks }\end{array}$ & SVR (95\% CI) & Duration, weeks & SVR (95\% CI) & \\
\hline \multicolumn{6}{|l|}{ GTla, TN } \\
\hline EBR/GZR & 12 & $0.929(0.900,0.952)$ & 12 & $0.937(0.874,0.974)$ & {$[26]$} \\
\hline PegIFN + RBV & 48 & $0.463(0.405,0.522)$ & N/A & - & {$[27]$} \\
\hline $\mathrm{LDV} / \mathrm{SOF}$ & 12 & $0.979(0.941,0.996)$ & 12 & $0.979(0.941,0.996)$ & \\
\hline OMB/PAR/RIT + DAS & 12 & $0.960(0.936,0.976)$ & 24 & $0.946(0.851,0.989)$ & {$[28]$} \\
\hline SOF/VEL & 12 & $0.970(0.924,0.992)$ & 12 & $0.970(0.924,0.992)$ & [29] \\
\hline GLE/PIB & 8 & $0.991(0.974,0.998)$ & 12 & $0.979(0.889,0.999)$ & {$[30,31]$} \\
\hline \multicolumn{6}{|l|}{$G T 1 b, T N$} \\
\hline EBR/GZR & 12 & $0.955(0.920,0.998)$ & 12 & $1.000(0.948,1.000)$ & [26] \\
\hline PegIFN + RBV & 48 & $0.463(0.405,0.522)$ & N/A & - & {$[27]$} \\
\hline LDV/SOF & 12 & $1.000(0.946,1.000)$ & 12 & $1.000(0.946,1.000)$ & \\
\hline $\mathrm{OMB} / \mathrm{PAR} / \mathrm{RIT}+\mathrm{DAS}$ & 12 & $1.000(0.983,1.000)$ & 12 & $1.000(0.872,1.000)$ & {$[28]$} \\
\hline SOF/VEL & 12 & $1.000(0.846,1.000)$ & 12 & $1.000(0.958,1.000)$ & [29] \\
\hline $\mathrm{DAC}+\mathrm{ASN}$ & 24 & $0.897(0.846,0.935)$ & 24 & $0.897(0.846-0.935)$ & {$[32]$} \\
\hline GLE/PIB & 8 & $0.991(0.974,0.998)$ & 12 & $1.00(0.910,1.000)$ & {$[30,31]$} \\
\hline \multicolumn{6}{|l|}{ GT1a, TE } \\
\hline EBR/GZR & 12 & $0.929(0.900,0.952)$ & 12 & $0.937(0.874,0.974)$ & [26] \\
\hline $\mathrm{LDV} / \mathrm{SOF}$ & 12 & $0.953(0.885,0.987)$ & 24 & $0.979(0.941,0.996)$ & \\
\hline $\mathrm{OMB} / \mathrm{PAR} / \mathrm{RIT}+\mathrm{DAS}$ & 12 & $0.960(0.918,0.984)$ & 24 & $0.946(0.851,0.989)$ & [28] \\
\hline SOF/VEL & 12 & $1.000(0.954,1.000)$ & 12 & $0.970(0.924,0.992)$ & [29] \\
\hline GLE/PIB & 8 & $0.991(0.974,0.998)$ & 12 & $0.979(0.889,0.999)$ & {$[30,31]$} \\
\hline \multicolumn{6}{|l|}{$G T 1 b, T E$} \\
\hline EBR/GZR & 12 & $0.955(0.920,0.977)$ & 12 & $1.000(0.948,1.000)$ & [26] \\
\hline $\mathrm{LDV} / \mathrm{SOF}$ & 12 & $0.870(0.664,0.972)$ & 24 & $1.000(0.858,1.000)$ & {$[33]$} \\
\hline $\mathrm{OMB} / \mathrm{PAR} / \mathrm{RIT}+\mathrm{DAS}$ & 12 & $1.000(0.960,1.000)$ & 12 & $1.000(0.894,1.000)$ & [28] \\
\hline SOF/VEL & 12 & $0.969(0.838,0.999)$ & 12 & $0.969(0.838,0.999)$ & [29] \\
\hline $\mathrm{DAC}+\mathrm{ASN}$ & 24 & $0.820(0.760,0.870)$ & 24 & $0.821(0.760,0.870)$ & {$[32]$} \\
\hline GLE/PIB & 8 & $0.991(0.974,0.998)$ & 12 & $1.000(0.910,1.000)$ & {$[31]$} \\
\hline
\end{tabular}

ASN, asunaprevir; DAC, daclatasvir; DAS, dasabuvir; EBR, elbasvir; F0, no fibrosis; F1, portal fibrosis without septa; F2, portal fibrosis with rare septa; F3, numerous septa without cirrhosis; F4, cirrhosis; GLE, glecaprevir; GT, genotype; GZR, grazoprevir; LDV, ledipasvir; OMB, ombitasvir; PAR, paritaprevir; PegIFN, pegylated interferon; PIB, pibrentasvir; RBV, ribavirin; SOF, sofosbuvir; SVR, sustained virologic response; TE, treatment-experienced; TN, treatment-naïve; VEL, velpatasvir

Table 2 Baseline characteristics of $\mathrm{HCV}$ patients

\begin{tabular}{lccccl}
\hline Variable & GT1a, TN & GT1a, TE & GT1b, TN & GT1b, TE & References \\
\hline Mean age, years & 50.6 & 44.7 & 58.1 & 55.3 & Hong Kong Public Hospital \\
Proportion males & 0.667 & 0.920 & 0.581 & 0.593 & Hong Kong Public Hospital \\
Fibrosis stage at baseline & & & & \\
F0 & 0.222 & 0.250 & 0.250 & 0.157 & Hong Kong Public Hospital \\
F1 & 0.222 & 0.250 & 0.250 & 0.157 & \\
F2 & 0.140 & 0.249 & 0.078 & 0.202 & \\
F3 & 0.083 & 0.063 & 0.081 & 0.192 & \\
F4 & 0.333 & 0.188 & 0.341 & 0.293 & \\
\hline
\end{tabular}

GT, genotype; HCV, hepatitis C virus; F0, no fibrosis; F1, portal fibrosis without septa; F2, portal fibrosis with rare septa; F3, numerous septa without cirrhosis; F4, cirrhosis; TE, treatment-experienced; TN, treatment-naïve 
Table 3 Probabilities, cost, and utility inputs

\begin{tabular}{|c|c|c|c|}
\hline Variable & Base case & Range & References \\
\hline Fibrosis progression & & & {$[3]$} \\
\hline F0 to F1 & 0.117 & $0.104-0.130$ & \\
\hline $\mathrm{F} 1$ to $\mathrm{F} 2$ & 0.085 & $0.075-0.096$ & \\
\hline $\mathrm{F} 2$ to $\mathrm{F} 3$ & 0.120 & $0.109-0.133$ & \\
\hline $\mathrm{F} 3$ to $\mathrm{F} 4$ & 0.116 & $0.104-0.129$ & \\
\hline Cirrhosis regression (SVR, F4 to SVR, F3) & 0.086 & $0.047-0.142$ & {$[34]$} \\
\hline \multicolumn{4}{|l|}{ Cirrhosis progression } \\
\hline F4 to DC & 0.029 & $0.010-0.039$ & {$[35-40]$} \\
\hline F4 to $\mathrm{HCC}$ & 0.028 & $0.010-0.079$ & {$[35,41-43]$} \\
\hline SVR, F4 to DC & 0.008 & $0.002-0.036$ & {$[44]$} \\
\hline SVR, F4 to HCC & 0.005 & $0.002-0.013$ & {$[40,42]$} \\
\hline Reinfection & & & {$[45-50]$} \\
\hline Annual probability & 0.047 & $0.036-0.061$ & \\
\hline Probability of chronicity & 0.430 & $0.290-0.580$ & \\
\hline Liver disease progression, DC to $\mathrm{HCC}$ & 0.068 & $0.030-0.083$ & {$[51]$} \\
\hline Probability of receiving liver transplant & & & [52-54] \\
\hline $\mathrm{DC}$ & 0.023 & $0.010-0.062$ & \\
\hline $\mathrm{HCC}$ & 0.040 & $0.000-0.140$ & \\
\hline \multicolumn{4}{|l|}{ Mortality rates } \\
\hline DC, first year & 0.140 & $0.065-0.190$ & [51] \\
\hline DC, subsequent years & 0.112 & $0.065-0.190$ & [35] \\
\hline HCC-related & 0.427 & $0.330-0.860$ & [51] \\
\hline Liver transplant, first year & 0.166 & $0.060-0.420$ & [55] \\
\hline Liver transplant, subsequent years & 0.044 & $0.060-0.420$ & {$[55]$} \\
\hline Annual health state costs, 2018 US\$ & & & {$[56,57]$} \\
\hline SVR, F0-F3 & 117 & $88-146$ & \\
\hline SVR, F4 & 333 & $249-416$ & \\
\hline DC & 928 & $696-1160$ & \\
\hline HCC, first year & 1919 & $1439-2399$ & \\
\hline HCC, subsequent years & 1542 & $1156-1927$ & \\
\hline Liver transplant, first year & 24,500 & $18,375-30,625$ & \\
\hline Liver transplant, subsequent years & 2038 & $1529-2548$ & \\
\hline Drug cost per week, 2018 US\$ & & & $\begin{array}{l}\text { Hong Kong } \\
\text { Public Hos- } \\
\text { pital }\end{array}$ \\
\hline EBR/GZR & 1029 & $722-1287$ & \\
\hline PegIFN & 76 & $57-96$ & \\
\hline RBV & 25 & $19-31$ & \\
\hline LDV/SOF & 2091 & $1568-2614$ & \\
\hline $\mathrm{OMB} / \mathrm{PAR} / \mathrm{RIT}+\mathrm{DAS}$ & 4182 & $3136-5227$ & \\
\hline SOF/VEL & 4182 & $3136-5227$ & \\
\hline DAC/ASN & 830 & $623-1038$ & \\
\hline GLE/PIB & 4182 & $3136-5227$ & \\
\hline \multicolumn{4}{|l|}{ Utilities } \\
\hline F0-F3 & 0.93 & $0.88-0.98$ & [58] \\
\hline F4 & 0.90 & $0.86-0.95$ & [58] \\
\hline DC & 0.80 & $0.76-0.84$ & [58] \\
\hline $\mathrm{HCC}$ & 0.79 & $0.75-0.83$ & [58] \\
\hline Post-liver transplant & 0.84 & $0.80-0.88$ & [58] \\
\hline Post-SVR, F0-F4 & 1.00 & $0.95-1.00$ & [20] \\
\hline Disutility, PegIFN-containing regimens & 0.236 & $0.224-0.248$ & [59] \\
\hline
\end{tabular}

ASN, asunaprevir; DAC, daclatasvir; DC, decompensated cirrhosis; EBR, elbasvir; F0, no fibrosis; F1, portal fibrosis without septa; F2, portal fibrosis with rare septa; F3, numerous septa without cirrhosis; F4, cirrhosis; GLE, glecaprevir; GT, genotype; GZR, grazoprevir; HCC, hepatocellular carcinoma; LDV, ledipasvir; OMB, ombitasvir; PAR, paritaprevir; PegIFN, pegylated interferon; PIT, pibrentasvir; RBV, ribavirin; RIT, ritonavir; SOF, sofosbuvir; SVR, sustained virologic response; US\$, United States dollars; VEL, velpatasvir 
disutility was applied to PegIFN + RBV due to its tolerability profile [59]. DAAs were assumed not to be associated with significant quality of life decrements.

\section{Model Analyses}

Incremental cost-utility ratios (ICURs) were the primary outcomes of all analyses. In the primary analysis, the cost-utility of each DAA relative to PegIFN + RBV was calculated as the difference in cost between PegIFN + RBV and the comparator (i.e., incremental cost) divided by the difference in QALYs (i.e., incremental QALYs). In cases in which total costs for EBR/GZR were lower, but QALYs were also lower, the results are presented as being cost-saving. In the secondary analyses, the cost-utility of DAAs was calculated using similar methods, but instead comparing each DAA to the next best option, removing options that are economically dominated (higher costs, but lower effectiveness) or weakly dominated (higher costs and effectiveness but with another option that has a lower ICUR). Results are presented separately by treatment history, subtype, and degree of liver fibrosis.

Efficacy, disease progression rates, and annual health state and medication costs were varied in one-way sensitivity analyses (OWSAs) according to the ranges presented in Tables 2 and 3. Probabilistic sensitivity analysis (PSA) was used to simultaneously vary the estimated values, drawing 1000 random samples from pre-defined distributions. Results of the PSA were presented using cost-effectiveness acceptability curves (CEACs). In addition, time horizons of 5,10 , and 20 years were explored for the primary analysis.

\section{Results}

In the primary analysis, all DAA regimens were more costly and more effective than PegIFN + RBV in TN FO-2 patients (Table 4). The ICUR versus PegIFN + RBV was lowest for EBR/GZR, at \$5015/QALY and \$8658/QALY in at GT1a and GT1b patients, respectively. ICURs for other DAAs versus PegIFN + RBV were as high as \$31,167/QALY for OMB/PAR/RIT+DAS in GT1 a patients and \$51,354/QALY for SOF/VEL in GT1b patients. Because QALYs were similar between treatments, cost was the primary driver of ICUR.

In secondary analyses including TN F3-4 patients and all TE patients, EBR/GZR was consistently the least costly option (Table 5). In GT1a, TE, F0-2 patients, only GLE/PIB was not dominated, with an ICUR of \$67,687/QALY versus EBR/GZR. In GT1b, TN, F0-2 patients, LDV/SOF, OMB/ PAR/RIT + DAS, and GLE/PIB were dominated by EBR/

Table 4 Primary analysis results: TN F0-2 patients, DAAs versus PegIFN + RBV

\begin{tabular}{|c|c|c|c|c|c|}
\hline Treatment regimen & $\begin{array}{l}\text { Total discounted } \\
\text { costs, } 2018 \text { US\$ }\end{array}$ & $\begin{array}{l}\text { Total discounted } \\
\text { QALYs }\end{array}$ & $\begin{array}{l}\text { Incremental costs, } \\
2018 \text { US\$ }\end{array}$ & $\begin{array}{l}\text { Incremental } \\
\text { QALYs }\end{array}$ & $\begin{array}{l}\text { ICUR, DAA versus } \\
\text { PegIFN + RBV ( } 2018 \text { US\$/ } \\
\text { QALY) }\end{array}$ \\
\hline \multicolumn{6}{|l|}{ GT1a } \\
\hline PegIFN + RBV & 6025 & 9.5944 & - & - & - \\
\hline EBR/GZR & 12,966 & 10.9784 & 6942 & 1.3840 & 5015 \\
\hline $\mathrm{LDV} / \mathrm{SOF}$ & 25,527 & 11.0728 & 19,502 & 1.4784 & 13,192 \\
\hline $\mathrm{OMB} / \mathrm{PAR} / \mathrm{RIT}+\mathrm{DAS} \pm \mathrm{RBV}$ & 50,619 & 11.0252 & 44,594 & 1.4308 & 31,167 \\
\hline SOF/VEL & 50,705 & 11.0545 & 44,680 & 1.4600 & 30,602 \\
\hline GLE/PIB & 33,962 & 11.1197 & 27,937 & 1.5253 & 18,316 \\
\hline \multicolumn{6}{|l|}{$G T 1 b$} \\
\hline PegIFN + RBV & 5537 & 7.9855 & - & - & - \\
\hline EBR/GZR & 12,660 & 8.8083 & 7123 & 0.8227 & 8658 \\
\hline $\mathrm{LDV} / \mathrm{SOF}$ & 25,261 & 8.8597 & 19,724 & 0.8742 & 22,563 \\
\hline $\mathrm{OMB} / \mathrm{PAR} / \mathrm{RIT}+\mathrm{DAS} \pm \mathrm{RBV}$ & 50,009 & 8.8600 & 44,472 & 0.8744 & 50,859 \\
\hline SOF/VEL & 50,416 & 8.8595 & 44,879 & 0.8739 & 51,354 \\
\hline $\mathrm{DAC}+\mathrm{ASN}$ & 19,326 & 8.6886 & 13,789 & 0.7031 & 19,612 \\
\hline GLE/PIB & 33,738 & 8.8694 & 28,202 & 0.8838 & 31,908 \\
\hline
\end{tabular}

ASN, asunaprevir; DAA, direct-acting antiviral; DAC, daclatasvir; DAS, dasabuvir; EBR, elbasvir; F0, no fibrosis; F1, portal fibrosis without septa; F2, portal fibrosis with rare septa; F3, numerous septa without cirrhosis; F4, cirrhosis; GLE, glecaprevir; GT, genotype; GZR, grazoprevir; ICUR, incremental cost-utility ratio; LDV, ledipasvir; OMB, ombitasvir; PAR, paritaprevir; PegIFN, pegylated interferon; PIB, pibrentasvir; QALY, quality-adjusted life year; RBV, ribavirin; RIT, ritonavir; SOF, sofosbuvir; TN, treatment-naïve; US\$, United States dollars; VEL, velpatasvir 
Table 5 Secondary analysis results: all other patient subgroups, all DAAs

\begin{tabular}{|c|c|c|c|c|c|}
\hline Treatment regimen & $\begin{array}{l}\text { Total discounted } \\
\text { costs, } 2018 \text { US\$ }\end{array}$ & $\begin{array}{l}\text { Total discounted } \\
\text { QALYs }\end{array}$ & $\begin{array}{l}\text { Incremental costs, } \\
2018 \text { US\$ }\end{array}$ & Incremental QALYs & $\begin{array}{l}\text { ICUR, EBR/GZR } \\
\text { versus comparator }\end{array}$ \\
\hline \multicolumn{6}{|l|}{ GTIa, TE, F0-2 } \\
\hline EBR/GZR & $\$ 13,194$ & 12.3517 & - & - & - \\
\hline $\mathrm{LDV} / \mathrm{SOF}$ & $\$ 25,806$ & 12.4140 & $12,611.8509$ & 0.0623 & Weakly dominated \\
\hline GLE/PIB & $\$ 34,164$ & 12.5375 & 8358.5081 & 0.1235 & $\$ 67,687$ \\
\hline $\mathrm{OMB} / \mathrm{PAR} / \mathrm{RIT}+\mathrm{DAS} \pm \mathrm{RBV}$ & $\$ 50,834$ & 12.4188 & $16,670.0178$ & -0.1187 & Dominated \\
\hline SOF/VEL & $\$ 50,832$ & 12.5318 & $16,667.5146$ & -0.0057 & Dominated \\
\hline \multicolumn{6}{|l|}{$G T 1 b, T E, F 0-2$} \\
\hline EBR/GZR & $\$ 12,786$ & 9.4048 & - & - & - \\
\hline LDV/SOF & $\$ 25,650$ & 9.2747 & $\$ 12,864$ & -0.1301 & Dominated \\
\hline $\mathrm{OMB} / \mathrm{PAR} / \mathrm{RIT}+\mathrm{DAS} \pm \mathrm{RBV}$ & $\$ 19,641$ & 9.1422 & $\$ 6856$ & -0.2626 & Dominated \\
\hline SOF/VEL & $\$ 33,849$ & 9.4814 & $\$ 21,063$ & 0.0766 & $\$ 275,053$ \\
\hline $\mathrm{DAC}+\mathrm{ASN}$ & $\$ 50,115$ & 9.4741 & $\$ 37,330$ & 0.0693 & $\$ 538,830$ \\
\hline GLE/PIB & $\$ 50,590$ & 9.4258 & $\$ 475$ & -0.0482 & Dominated \\
\hline \multicolumn{6}{|l|}{$G T 1 a, T N, F 3-4$} \\
\hline EBR/GZR & $\$ 14,760$ & 7.4043 & - & - & - \\
\hline $\mathrm{LDV} / \mathrm{SOF}$ & $\$ 27,265$ & 7.6394 & $\$ 12,505$ & 0.2351 & $\$ 53,184$ \\
\hline $\mathrm{DAC}+\mathrm{ASN}$ & $\$ 48,912$ & 7.5967 & $\$ 21,647$ & -0.0427 & Dominated \\
\hline SOF/VEL & $\$ 52,490$ & 7.5442 & $\$ 25,225$ & -0.0953 & Dominated \\
\hline $\mathrm{OMB} / \mathrm{PAR} / \mathrm{RIT}+\mathrm{DAS} \pm \mathrm{RBV}$ & $\$ 91,051$ & 7.3000 & $\$ 63,786$ & -0.3394 & Dominated \\
\hline \multicolumn{6}{|l|}{$G T 1 b, T N, F 3-4$} \\
\hline EBR/GZR & $\$ 14,097$ & 6.1911 & - & - & - \\
\hline $\mathrm{DAC}+\mathrm{ASN}$ & $\$ 20,910$ & 5.8695 & $\$ 6814$ & -0.3217 & Dominated \\
\hline LDV/SOF & $\$ 26,748$ & 6.2152 & $\$ 12,651$ & 0.0241 & Weakly dominated \\
\hline GLE/PIB & $\$ 48,367$ & 6.2139 & $\$ 27,457$ & 0.3444 & $\$ 79,723$ \\
\hline $\mathrm{OMB} / \mathrm{PAR} / \mathrm{RIT}+\mathrm{DAS} \pm \mathrm{RBV}$ & $\$ 51,495$ & 6.2153 & $\$ 3128$ & 0.0015 & $\$ 2,127,868$ \\
\hline SOF/VEL & $\$ 51,903$ & 6.2150 & $\$ 407$ & -0.0003 & Dominated \\
\hline \multicolumn{6}{|l|}{$G T 1 a, T E, F 3-4$} \\
\hline EBR/GZR & $\$ 15,063$ & 8.2813 & - & - & - \\
\hline $\mathrm{LDV} / \mathrm{SOF}$ & $\$ 47,371$ & 8.3620 & $\$ 32,308$ & 0.0807 & Weakly dominated \\
\hline GLE/PIB & $\$ 49,214$ & 8.5085 & $\$ 34,151$ & 0.2272 & Weakly dominated \\
\hline SOF/VEL & $\$ 52,701$ & 8.5922 & $\$ 37,639$ & 0.3110 & $\$ 121,028$ \\
\hline $\mathrm{OMB} / \mathrm{PAR} / \mathrm{RIT}+\mathrm{DAS} \pm \mathrm{RBV}$ & $\$ 91,344$ & 8.2258 & $\$ 38,643$ & -0.3665 & Dominated \\
\hline \multicolumn{6}{|l|}{$G T 1 b, T E, F 3-4$} \\
\hline EBR/GZR & $\$ 14,299$ & 6.7769 & - & - & - \\
\hline $\mathrm{DAC}+\mathrm{ASN}$ & $\$ 21,344$ & 6.1507 & $\$ 7045$ & -0.6262 & Dominated \\
\hline LDV/SOF & $\$ 46,839$ & 6.6892 & $\$ 32,540$ & -0.0877 & Dominated \\
\hline GLE/PIB & $\$ 48,568$ & 6.8034 & $\$ 34,269$ & 0.0265 & $\$ 1,293,591$ \\
\hline $\mathrm{OMB} / \mathrm{PAR} / \mathrm{RIT}+\mathrm{DAS} \pm \mathrm{RBV}$ & $\$ 51,696$ & 6.8054 & $\$ 3128$ & 0.0020 & $\$ 1,587,177$ \\
\hline SOF/VEL & $\$ 52,196$ & 6.6982 & $\$ 500$ & -0.1072 & Dominated \\
\hline
\end{tabular}

ASN, asunaprevir; DAA, direct-acting antiviral; DAC, daclatasvir; DAS, dasabuvir; EBR, elbasvir; F0, no fibrosis; F1, portal fibrosis without septa; F2, portal fibrosis with rare septa; F3, numerous septa without cirrhosis; F4, cirrhosis; GLE, glecaprevir; GT, genotype; GZR, grazoprevir; ICUR, incremental cost-utility ratio; LDV, ledipasvir; OMB, ombitasvir; PAR, paritaprevir; PegIFN, pegylated interferon; PIB, pibrentasvir; QALYs, quality-adjusted life years; RBV, ribavirin; RIT, ritonavir; SOF, sofosbuvir; TE, treatment-experienced; TN, treatment-naïve; US\$, United States dollars; VEL, velpatasvir

GZR, while SOF/VEL and DAC + ASN had high ICURs compared to EBR/GZR. In GT1a, TN, F3-4 patients, only LDV/SOF was not dominated by EBR/GZR; in GT1b, TN, F3-4 patients, only GLE/PIB and OMB/PAR/RIT + DAS were not dominated. Finally, in GT1a, TE, F3-4 patients only SOF/VEL was not dominated, and in GT1b, TE, F3-4 patients, GLE/PIB and OMB/PAR/RIT + DAS had high 
ICURs compared to EBR/GZR and all other DAAs were dominated.

In the primary analysis, OWSAs showed that varying the model parameters within the specified ranges did not impact the conclusion that all DAAs are cost-effective compared to PegIFN + RBV. One-way sensitivity analyses in the secondary analyses showed that model results were sensitive to variability in SVRs within their 95\% CIs for EBR/GZR and other DAAs for some comparisons (data not shown), with results switching between cost-saving and economically dominant without impacting the overall conclusion of EBR/GZR being economically favored.

Probabilistic sensitivity analyses for the primary comparison in TN F0-2 patients showed that PegIFN + RBV was most likely to be cost-effective at a willingness-to-pay (WTP) threshold up to \$5000/QALY in GT1a patients, after which EBR/GZR was most likely to be cost-effective (Fig. 2a). In GT1b patients, PegIFN + RBV was most likely to be cost-effective at a WTP threshold of $\$ 0$ to $\$ 11,000$ / QALY and EBR/GZR was most likely to be cost-effective thereafter (Fig. 2b).

In GT1a patients, EBR/GZR was also most likely to be cost-effective at WTP thresholds up to $\$ 116,000 / \mathrm{QALY}$ in TE F0-2 patients (Fig. 2c); up to \$70,000/QALY in TN F3-4 patients (Fig. 2e); and up to $\$ 111,000 /$ QALY in the TE F3-4 subgroup (Fig. 2g). In GT1b patients who are TN F3-4 and both TE subgroups, EBR/GZR was cost-effective in more than $90 \%$ of iterations at WTP thresholds up to \$150,000/QALY (Fig. 2d, f, h).

ICURs for the primary analysis decreased with increasing time horizon. ICURs for EBR/GZR were \$26,532/QALY, $\$ 15,326 / \mathrm{QALY}$, and \$7663/QALY at time horizons of 5, 10, and 20 years, respectively. ICURs for OMB/PAR/RIT + DAS and SOF/VEL were $>\$ 150,000$ at a 5-year time horizon but fell to $\$ 91,235 / \mathrm{QALY}$ and $\$ 88,628 / \mathrm{QALY}$ at 10 years and $\$ 46,805 / \mathrm{QALY}$ and $\$ 45,822 / \mathrm{QALY}$ at 20 years. Other DAAs had ICURs $<\$ 100,000 /$ QALY at all time horizons.

\section{Discussion}

The primary objective of the present study was to evaluate the cost-effectiveness of DAAs compared to PegIFN + RBV, the current standard of care, in treatment-naïve (TN) patients with GT1 CHC infection without advanced liver disease. The secondary objective was to compare DAAs in treatment-experienced (TE) patients as well as TN patients with advanced liver disease.

The WHO has defined interventions with an incremental cost per disability-adjusted life year (DALY) less than the country's annual gross domestic product (GDP) per capita as very cost-effective, whereas interventions with an incremental cost per DALY of more than three times GDP per capita are not cost-effective [61]. Using these thresholds and extrapolating DALYs to QALYs produces cost-effectiveness thresholds of approximately \$46,000/QALY for very cost-effective interventions and more than $\$ 138,000$ / QALY for interventions unlikely to be cost-effective in Hong Kong. At these thresholds, all DAAs can be considered very cost-effective compared to PegIFN + RBV in TN patients with GT1 CHC and F0-2 fibrosis, except OMB/ $\mathrm{PAR} / \mathrm{RIT}+\mathrm{DAS} \pm \mathrm{RBV}$ and SOF/VEL in GT1b patients. Among the DAAs currently marketed or anticipated to be marketed soon in Hong Kong, EBR/GZR had the lowest cost per additional QALY gained compared to PegIFN + RBV and thus represents the best value for investment in treatment of GT1 TN F0-2 patients with CHC.

An estimated 39\% of patients diagnosed with $\mathrm{CHC}$ in Hong Kong already have significant fibrosis or cirrhosis at their first fibrosis assessment [2]. Treatment is urgent to stop further progression of liver disease, so DAAs are typically reserved for these patients in Hong Kong and other resourcelimited countries. In the near future, the government will certainly expand DAA treatment eligibility to all CHC patients in order to achieve the WHO's 2030 target. Given the anticipated expansion of treatment criteria in Hong Kong and the availability of multiple all-oral DAA regimens with similar efficacy, this study addressed the important question of which all-oral DAA regimens are the most cost-effective in maximizing outcomes of healthcare dollars spent. EBR/ GZR, being the least costly DAA in Hong Kong, and with similar or superior efficacy to comparators, can thus be considered a cost-effective option for treatment of GT1 CHC in Hong Kong.

Previous economic analyses support our conclusion of cost-effectiveness results for EBR/GZR and other DAAs compared to PegIFN + RBV. In a previous model of GT1infected $\mathrm{CHC}$ patients using a decision tree structure, SOF, LDV/SOF, and OMB/PAR/RIT + DAS were all cost-effective compared to PegIFN + RBV, regardless of treatment history and presence of cirrhosis, with ICURs less than US $\$ 30,000$ per additional cure [62]. In addition, hypothetical highly effective DAAs (defined as having an SVR of $100 \%$ ) were projected to be the most cost-effective compared to PegIFN + RBV at a price of up to US $\$ 43,553$ in countries where $\mathrm{SOF}+\mathrm{PegIFN}+\mathrm{RBV}$ is the standard of practice and up to US\$56,985 where boceprevir + PegIFN + RBV is the standard [56]. Actual costs of DAAs in Hong Kong (Table 3) are lower than these estimates, further supporting the agents' cost-effectiveness versus PegIFN + RBV.

While the Second Panel on Cost-effectiveness in Health and Medicine recommends that models should include both the healthcare and societal perspectives [63], we included only the healthcare perspective in this model. In Hong Kong, reimbursement decisions are made by public hospitals and thus the payer perspective is most relevant to 
A GT1a, TN, FO-2

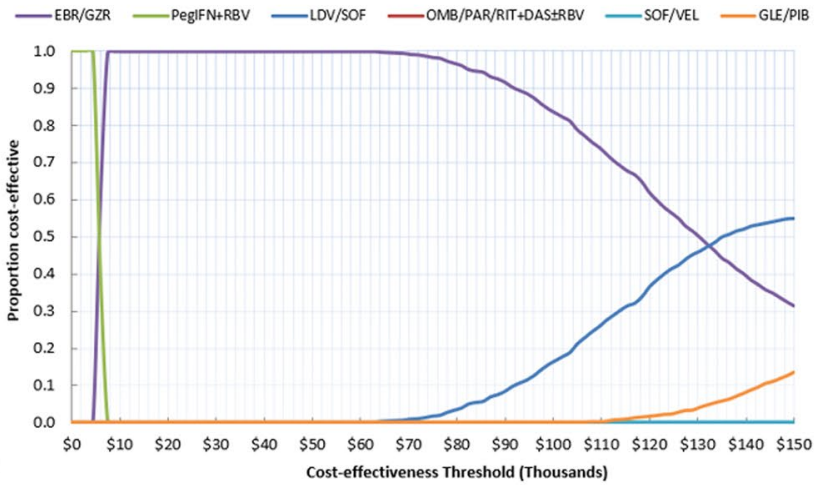

C GT1a, TE, FO-2

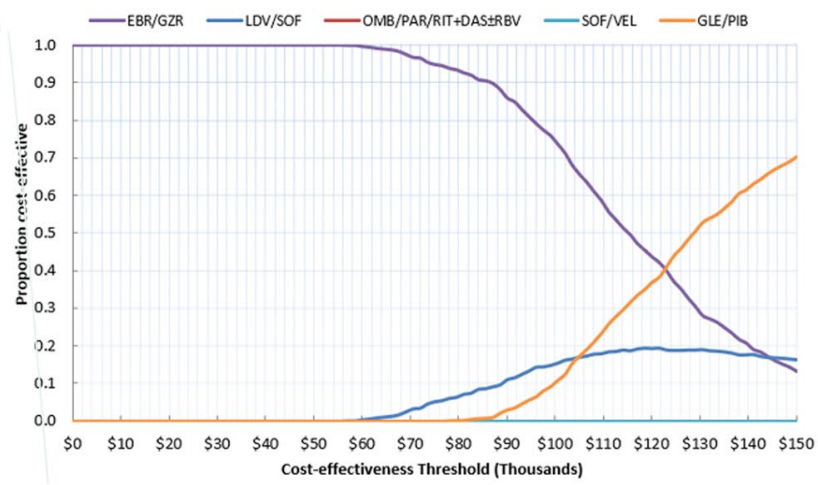

\section{$E$ GT13, TN, F3-4}

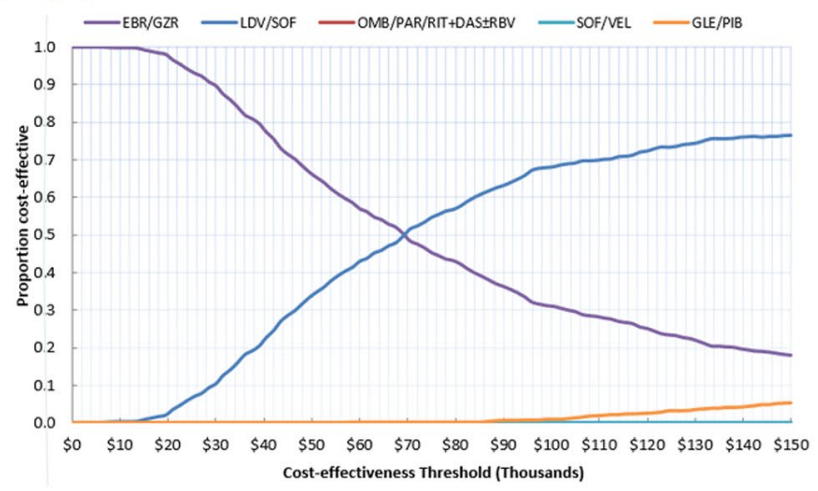

\section{G GT13, TE, F3-4}

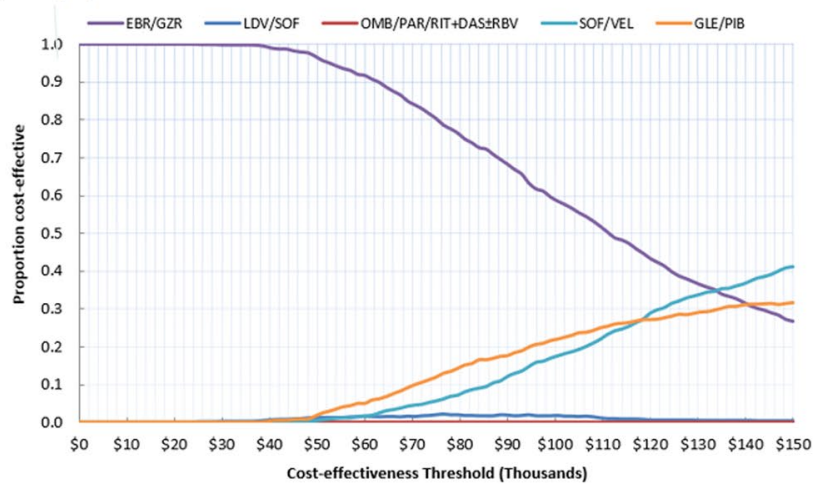

Fig. 2 Cost-effectiveness acceptability curves. ASN, asunaprevir; DAC, daclatasvir; DAS, dasabuvir; EBR, elbasvir; GLE, glecaprevir; GT, genotype; GZR, grazoprevir; LDV, ledipasvir; OMB, ombitasvir;
B GT1b, TN, F0-2

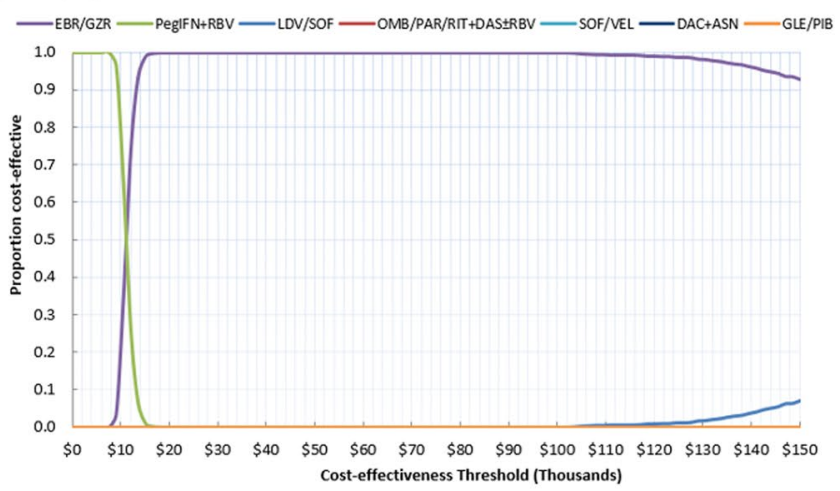

\section{GT1b, TE, F0-2}

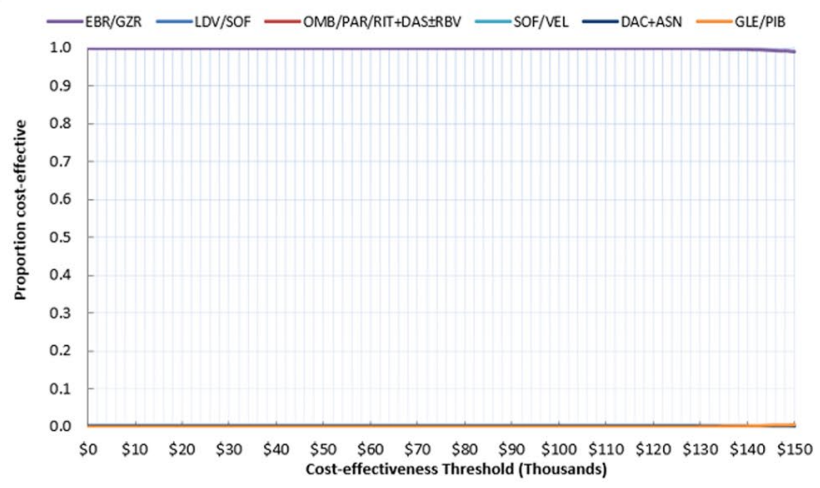

\section{$F_{\text {GT1b, TN, F3-4 }}$}

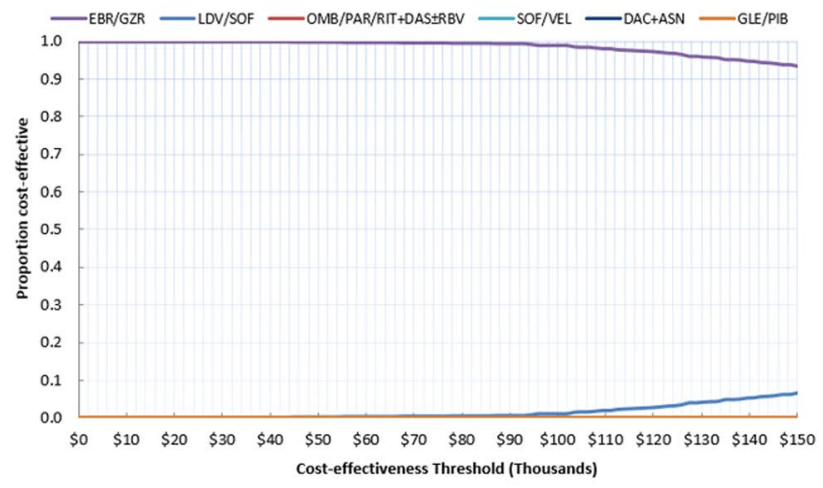

\section{$\mathrm{H}_{\mathrm{GT}} \mathrm{b}, \mathrm{TE}, \mathrm{F3}-4$}

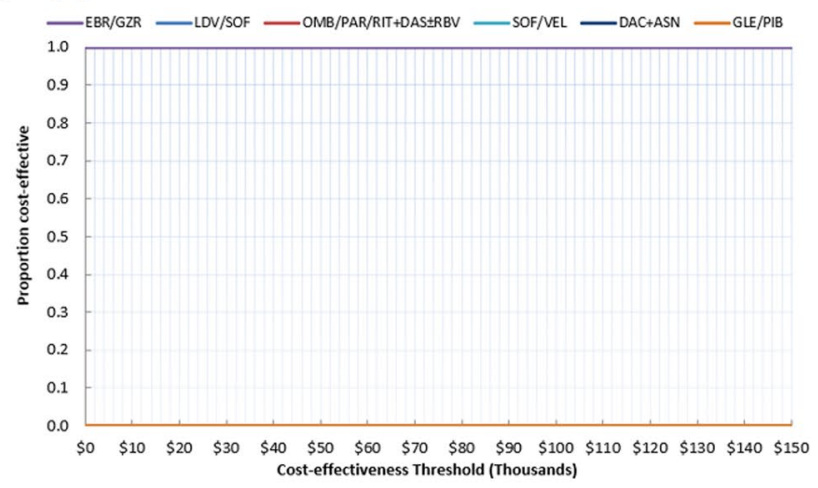

PAR, paritaprevir; PegIFN, pegylated interferon; PIB, pibrentasvir; $\mathrm{RBV}$, ribavirin; SOF, sofosbuvir; TE, treatment-experienced; TN, treatment-naïve; VEL, velpatasvir 
capture the costs in the healthcare system. This perspective is consistent with previously published $\mathrm{HCV}$ models, as highlighted in a recent systematic review of cost-utility analyses in which 30 out of 36 published models reported using a payer perspective [64].

With all the results analyzed in the present study, it seems that EBR/GZR outperformed other DDAs in treating genotype 1 disease in terms of the cost-effectiveness. Healthcare policy makers in Hong Kong should seriously consider this information where not all HCV patients are eligible for receiving treatment because of cost consideration. However, it should also be noted that different healthcare financial situations exist in different countries; the generalization of the findings of this present study needs to be specifically examined in individual countries.

Our analysis has some limitations. First, assumptions in the model regarding the natural history and management of liver disease (e.g., assuming DC and HCC are mutually exclusive states) may overestimate the clinical benefits of HCV treatment. Real-world data on the effectiveness of DAAs are emerging, but are currently limited to OMB/ PAR/RIT + DAS (SVR, 95-100\%) and LDV/SOF (SVR, $92.9 \%)[2,65]$. Therefore, efficacy inputs for the model were obtained from clinical trials, without adjustment for between-trial heterogeneity. Within some subgroups, treatment efficacy was estimated from subpopulations with small sample sizes and wide confidence intervals around SVR estimates. However, variations of SVR within these intervals did not change the overall model conclusions. Adherence was not considered in the model, as data were not available for all comparators and the impact of nonadherence on outcomes is unclear. Utility values are not country specific due to lack of local data. Furthermore, data on $\mathrm{HCV}$ reinfection rates were not specific to Hong Kong due to lack of data. One study from Taiwan reported a reinfection rate of 0.082 per year [66] (vs. 0.047 per year used in the model), which would have increased costs and decreased QALYs in all groups. Finally, it was assumed that patients in the model who were reinfected (with chronicity) after achieving SVR would not receive any subsequent HCV treatment, increasing potential costs while decreasing utility.

In conclusion, EBR/GZR is cost-effective compared to PegIFN + RBV in GT1 TN F0-2 patients and is more costeffective versus PegIFN + RBV than other DAAs. In GT1 TE F0-2 patients, and in TN and TE F3-4 patients, EBR/ GZR is the least costly DAA and is economically dominant over most other DAAs.

Funding This study was supported by Merck Sharp \& Dohme Corp., a subsidiary of Merck \& Co., Inc., Kenilworth, NJ, USA.

\section{Compliance with Ethical Standards}

Conflict of interest MFY, SHL, WKS, and LYM declare no conflicts of interest. DCH, MYKL, and TKK are employees of Merck Sharp \& Dohme (Asia) Ltd. AP is an employee of Merck \& Co., Inc. SLC is an employee of Pharmerit International, which received consulting fees from Merck \& Co., Inc., for this work.

Ethical approval This article does not contain any studies with human participants or animals performed by any of the authors. For this type of study, formal consent is not required.

Open Access This article is licensed under a Creative Commons Attribution-NonCommercial 4.0 International License, which permits any non-commercial use, sharing, adaptation, distribution and reproduction in any medium or format, as long as you give appropriate credit to the original author(s) and the source, provide a link to the Creative Commons licence, and indicate if changes were made. The images or other third party material in this article are included in the article's Creative Commons licence, unless indicated otherwise in a credit line to the material. If material is not included in the article's Creative Commons licence and your intended use is not permitted by statutory regulation or exceeds the permitted use, you will need to obtain permission directly from the copyright holder.To view a copy of this licence, visit http://creativecommons.org/licenses/by-nc/4.0/.

\section{References}

1. Wang H, Naghavi M, Allen C, et al. Global, regional, and national life expectancy, all-cause mortality, and cause-specific mortality for 249 causes of death, 1980-2015: a systematic analysis for the Global Burden of Disease Study 2015. Lancet. 2016;388:1459-1544.

2. Hui YT, Wong GLH, Fung JYY, et al. Territory-wide population-based study of chronic hepatitis $\mathrm{C}$ infection and implications for hepatitis elimination in Hong Kong. Liver Int. 2018;38:1911-1919.

3. Thein HH, Yi Q, Dore GJ, et al. Estimation of stage-specific fibrosis progression rates in chronic hepatitis $\mathrm{C}$ virus infection: a metaanalysis and meta-regression. Hepatology. 2008;48:418-431.

4. Akhtar E, Manne V, Saab S. Cirrhosis regression in hepatitis C patients with sustained virological response after antiviral therapy: a meta-analysis. Liver Int. 2015;35:30-36.

5. Smith-Palmer J, Cerri K, Valentine W. Achieving sustained virologic response in hepatitis C: a systematic review of the clinical, economic and quality of life benefits. BMC Infect Dis. 2015;15:19.

6. Bonkovsky HL, Snow KK, Malet PF, et al. Health-related quality of life in patients with chronic hepatitis $\mathrm{C}$ and advanced fibrosis. J Hepatol. 2007;46:420-431.

7. Younossi Z, Park H, Henry L, et al. Extrahepatic manifestations of hepatitis C: a meta-analysis of prevalence, quality of life, and economic burden. Gastroenterology. 2016;150:1599-1608.

8. World Health Organization. Combating Hepatitis B and C to Reach Elimination by 2030. Available at: https://apps.who.int/ iris/bitstream/handle/10665/206453/WHO_HIV_2016.04_eng. pdf;jsessionid=4BD913237991690DE2A6A6FDE7DFD5 A8? sequence $=1$. Accessed February 5, 2019.

9. Poordad F, Dieterich D. Treating hepatitis C: current standard of care and emerging direct-acting antiviral agents. $J$ Viral Hepat. 2012;19:449-464. 
10. Feeney ER, Chung RT. Antiviral treatment of hepatitis C. BMJ. 2014;348:g3308.

11. Marshall AD, Cunningham EB, Nielsen S, et al. Restrictions for reimbursement of interferon-free direct-acting antiviral drugs for HCV infection in Europe. Lancet Gastroenterol Hepatol. 2018;3:125-133.

12. Corman S, Elbasha EH, Michalopoulos SN, et al. Cost-utility of elbasvir/grazoprevir in patients with chronic hepatitis $\mathrm{C}$ genotype 1 infection. Value Health. 2017;20:1110-1120.

13. Buti M, Medina M, Casado MA, et al. A cost-effectiveness analysis of peginterferon alfa-2b plus ribavirin for the treatment of naive patients with chronic hepatitis C. Aliment Pharmacol Ther. 2003;17:687-694.

14. Salomon JA, Weinstein MC, Hammitt JK, et al. Cost-effectiveness of treatment for chronic hepatitis $\mathrm{C}$ infection in an evolving patient population. JAMA. 2003;290:228-237.

15. Siebert U, Sroczynski G, Rossol S, et al. Cost effectiveness of peginterferon alpha- $2 b$ plus ribavirin versus interferon alpha- $2 b$ plus ribavirin for initial treatment of chronic hepatitis C. Gut. 2003;52:425-432.

16. Sullivan SD, Craxi A, Alberti A, et al. Cost effectiveness of peginterferon alpha-2a plus ribavirin versus interferon alpha- $2 b$ plus ribavirin as initial therapy for treatment-naive chronic hepatitis C. Pharmacoeconomics. 2004;22:257-265.

17. Younossi ZM, Singer ME, McHutchison JG, et al. Cost effectiveness of interferon alpha2b combined with ribavirin for the treatment of chronic hepatitis C. Hepatology. 1999;30:1318-1324.

18. Chhatwal J, Ferrante SA, Brass C, et al. Cost-effectiveness of boceprevir in patients previously treated for chronic hepatitis C genotype 1 infection in the United States. Value Health. 2013;16:973-986.

19. Elbasha EH, Chhatwal J, Ferrante SA, et al. Cost-effectiveness analysis of boceprevir for the treatment of chronic hepatitis $\mathrm{C}$ virus genotype 1 infection in Portugal. Appl Health Econ Health Policy. 2013;11:65-78.

20. Ferrante SA, Chhatwal J, Brass CA, et al. Boceprevir for previously untreated patients with chronic hepatitis $C$ Genotype 1 infection: a US-based cost-effectiveness modeling study. BMC Infect Dis. 2013;13:190.

21. Elbasha EH, Robertson MN, Nwankwo C. The cost-effectiveness of testing for NS5a resistance-associated polymorphisms at baseline in genotype 1a-infected (treatment-naive and treatment-experienced) subjects treated with all-oral elbasvir/grazoprevir regimens in the United States. Aliment Pharmacol Ther. 2017;45:455-467.

22. Siebert U, Alagoz O, Bayoumi AM, et al. State-transition modeling: a report of the ISPOR-SMDM modeling good research practices task force-3. Value Health. 2012;15:812-820.

23. Chen Yi Mei SLG, Thompson AJ, Christensen B, et al. Sustained virological response halts fibrosis progression: a long-term followup study of people with chronic hepatitis C infection. PLOS ONE. 2017;12:e0185609.

24. Lee YA, Friedman SL. Reversal, maintenance or progression: what happens to the liver after a virologic cure of hepatitis C? Antiviral Res. 2014;107:23-30.

25. Alavian SM, Rezaee-Zavareh MS. Daclatasvir-based treatment regimens for hepatitis $\mathrm{C}$ virus infection: a systematic review and meta-analysis. Hepat Mon. 2016;16:e41077.

26. ZEPATIER package insert, 26 June 2019 update. Available at: https://www.ema.europa.eu/en/medicines/human/EPAR/zepat ier\#product-information-section. Accessed February 25, 2020.

27. Fried MW, Shiffman ML, Reddy KR, et al. Peginterferon alfa-2a plus ribavirin for chronic hepatitis $\mathrm{C}$ virus infection. $N$ Engl $J$ Med. 2002;347:975-982.

28. VIEKIRAX package insert, 14 November 2019 update. Available at: https://www.ema.europa.eu/en/documents/product-informatio n/viekirax-epar-product-information_en.pdf. Accessed February 25, 2020 .

29. Feld JJ, Jacobson IM, Hezode C, et al. Sofosbuvir and Velpatasvir for HCV Genotype 1, 2, 4, 5, and 6 Infection. $N$ Engl J Med. 2015;373:2599-2607.

30. Zeuzem S, Foster GR, Wang S, et al. Glecaprevir-pibrentasvir for 8 or 12 weeks in HCV genotype 1 or 3 infection. $N$ Engl J Med. 2018;378:354-369.

31. Forns X, Lee SS, Valdes J, et al. Glecaprevir plus pibrentasvir for chronic hepatitis $C$ virus genotype $1,2,4,5$, or 6 infection in adults with compensated cirrhosis (EXPEDITION-1): a singlearm, open-label, multicentre phase 3 trial. Lancet Infect Dis. 2017;17:1062-1068.

32. Manns M, Pol S, Jacobson IM, et al. All-oral daclatasvir plus asunaprevir for hepatitis $\mathrm{C}$ virus genotype $1 \mathrm{~b}$ : a multinational, phase 3, multicohort study. Lancet. 2014;384:1597-1605.

33. Afdhal N, Reddy KR, Nelson DR, et al. Ledipasvir and sofosbuvir for previously treated HCV genotype 1 infection. $N$ Engl J Med. 2014;370:1483-1493.

34. D’Ambrosio R, Aghemo A, Rumi MG, et al. A morphometric and immunohistochemical study to assess the benefit of a sustained virological response in hepatitis $\mathrm{C}$ virus patients with cirrhosis. Hepatology. 2012;56:532-543.

35. Fattovich G, Giustina G, Degos F, et al. Morbidity and mortality in compensated cirrhosis type C: a retrospective follow-up study of 384 patients. Gastroenterology. 1997;112:463-472.

36. Gentilini P, Laffi G, La Villa G, et al. Long course and prognostic factors of virus-induced cirrhosis of the liver. Am J Gastroenterol. 1997;92:66-72.

37. Serfaty L, Aumaitre H, Chazouilleres O, et al. Determinants of outcome of compensated hepatitis $\mathrm{C}$ virus-related cirrhosis. Hepatology. 1998;27:1435-1440.

38. Benvegnu L, Gios M, Boccato S, et al. Natural history of compensated viral cirrhosis: a prospective study on the incidence and hierarchy of major complications. Gut. 2004;53:744-749.

39. Sangiovanni A, Prati GM, Fasani P, et al. The natural history of compensated cirrhosis due to hepatitis $C$ virus: a 17-year cohort study of 214 patients. Hepatology. 2006;43:1303-1310.

40. van der Meer AJ, Veldt BJ, Feld JJ, et al. Association between sustained virological response and all-cause mortality among patients with chronic hepatitis $\mathrm{C}$ and advanced hepatic fibrosis. JAMA. 2012;308:2584-2593.

41. Tsukuma H, Hiyama T, Tanaka S, et al. Risk factors for hepatocellular carcinoma among patients with chronic liver disease. N Engl J Med. 1993;328:1797-1801.

42. Bruno S, Silini E, Crosignani A, et al. Hepatitis C virus genotypes and risk of hepatocellular carcinoma in cirrhosis: a prospective study. Hepatology. 1997;25:754-758.

43. Yoshida H, Shiratori Y, Moriyama M, et al. Interferon therapy reduces the risk for hepatocellular carcinoma: national surveillance program of cirrhotic and noncirrhotic patients with chronic hepatitis C in Japan. IHIT Study Group. Inhibition of Hepatocarcinogenesis by Interferon Therapy. Ann Intern Med. 1999;131:174-181.

44. Tateyama M, Yatsuhashi H, Taura N, et al. Alpha-fetoprotein above normal levels as a risk factor for the development of hepatocellular carcinoma in patients infected with hepatitis $\mathrm{C}$ virus. J Gastroenterol. 2011;46:92-100.

45. Page K, Hahn JA, Evans J, et al. Acute hepatitis C virus infection in young adult injection drug users: a prospective study of incident infection, resolution, and reinfection. J Infect Dis. 2009;200:1216-1226.

46. Mehta SH, Cox A, Hoover DR, et al. Protection against persistence of hepatitis C. Lancet. 2002;359:1478-1483.

47. Grebely J, Conway B, Raffa JD, et al. Hepatitis C virus reinfection in injection drug users. Hepatology. 2006;44:1139-1145. 
48. Osburn WO, Fisher BE, Dowd KA, et al. Spontaneous control of primary hepatitis $\mathrm{C}$ virus infection and immunity against persistent reinfection. Gastroenterology. 2010;138:315-324.

49. Sacks-Davis R, Aitken CK, Higgs P, et al. High rates of hepatitis $\mathrm{C}$ virus reinfection and spontaneous clearance of reinfection in people who inject drugs: a prospective cohort study. PLOS ONE. 2013;8:e80216.

50. Page K, Osburn W, Evans J, et al. Frequent longitudinal sampling of hepatitis $\mathrm{C}$ virus infection in injection drug users reveals intermittently detectable viremia and reinfection. Clin Infect Dis. 2013;56:405-413.

51. Planas R, Balleste B, Alvarez MA, et al. Natural history of decompensated hepatitis $C$ virus-related cirrhosis. A study of 200 patients. J Hepatol. 2004;40:823-830.

52. Thuluvath PJ, Guidinger MK, Fung JJ, et al. Liver transplantation in the United States, 1999-2008. Am J Transplant. 2010;10:1003-1019.

53. Davis GL, Alter MJ, El-Serag H, et al. Aging of hepatitis $\mathrm{C}$ virus (HCV)-infected persons in the United States: a multiple cohort model of HCV prevalence and disease progression. Gastroenterology. 2010;138:513-521.

54. Lang K, Danchenko N, Gondek K, et al. The burden of illness associated with hepatocellular carcinoma in the United States. $J$ Hepatol. 2009;50:89-99.

55. Wolfe RA, Roys EC, Merion RM. Trends in organ donation and transplantation in the United States, 1999-2008. Am J Transplant. 2010;10:961-972.

56. Lo AO, Chan HL, Wong VW, et al. Cost-effectiveness of the highly effective direct-acting antivirals in the treatment of chronic hepatitis C in Hong Kong. $J$ Gastroenterol Hepatol. 2017;32:1071-1078.

57. Chen GF, Wei L, Chen J, et al. Will sofosbuvir/ledipasvir (Harvoni) be cost-effective and affordable for Chinese patients infected with hepatitis $\mathrm{C}$ virus? An economic analysis using real-world data. PLOS ONE. 2016;11:e0155934.

58. Chong CA, Gulamhussein A, Heathcote EJ, et al. Health-state utilities and quality of life in hepatitis C patients. Am J Gastroenterol. 2003;98:630-638.
59. Younossi ZM, Stepanova M, Henry L, et al. An in-depth analysis of patient-reported outcomes in patients with chronic hepatitis $\mathrm{C}$ treated with different anti-viral regimens. Am J Gastroenterol. 2016;111:808-816.

60. Hanmer J, Lawrence WF, Anderson JP, et al. Report of nationally representative values for the noninstitutionalized US adult population for 7 health-related quality-of-life scores. Med Decis Mak. 2006;26:391-400.

61. Marseille E, Larson B, Kazi DS, et al. Thresholds for the costeffectiveness of interventions: alternative approaches. Bull World Health Organ. 2015;93:118-124.

62. Li X, Chan NS, Tam AW, et al. Budget impact and cost-effectiveness analyses of direct-acting antivirals for chronic hepatitis C virus infection in Hong Kong. Eur J Clin Microbiol Infect Dis. 2017:36:1801-1809.

63. Sanders GD, Neumann PJ, Basu A, et al. Recommendations for conduct, methodological practices, and reporting of cost-effectiveness analyses: second panel on cost-effectiveness in health and medicine. JAMA. 2016;316:1093-1103.

64. Puig-Junoy J, Pascual-Argente N, Puig-Codina L, et al. Costutility analysis of second-generation direct-acting antivirals for hepatitis C: a systematic review. Expert Rev Gastroenterol Hepatol. 2018;12:1251-1263.

65. Chan HL, Tsang OT, Hui YT, et al. Real-life efficacy and safety of paritaprevir/ritonavir, ombitasvir, and dasabuvir in chronic hepatitis C patients in Hong Kong. J Gastroenterol Hepatol. 2017;32:1230-1233.

66. Huang CF, Yeh ML, Huang CI, et al. Risk of hepatitis C virus related hepatocellular carcinoma between subjects with spontaneous and treatment-induced viral clearance. Oncotarget. 2017;8:43925-43933.

Publisher's Note Springer Nature remains neutral with regard to jurisdictional claims in published maps and institutional affiliations. 